\title{
Role of Peripheral Analysis Methods in Adoption of Successful KPIs for a Research Institute Working Towards Commercial Agriculture
}

\author{
Prabath Chaminda Abeysiriwardana ${ }^{1,2}\left(\mathbb{D} \cdot\right.$ Udith K. Jayasinghe-Mudalige $^{1}(\mathbb{C}$
}

Received: 2 January 2021 / Accepted: 19 March 2021 / Published online: 12 April 2021

(c) Global Institute of Flexible Systems Management 2021

\begin{abstract}
The outcome of the performance measurement would be more convergent at decision making if KPIs are tightly bound with organization culture along with organizational design. Peripheral analysis methodologies which are taken into the lens before the performance management have a major role in understanding the organizational culture and dynamism behind the organizational design to identify strengths, weaknesses, and opportunities in a research institute's work for commercial agriculture development. The lack of a proper analyzing system to understand the critical success factors of a research institute towards innovative commercial agriculture has hampered the establishment of a good performance management system in research institutes towards this end. In this context, we highlight the most important avenues that could significantly improve the quality of performance, if used properly in the management of a research institute's work for commercial agriculture. How those management practices and tools could be streamlined by introducing new guidelines and policies in organization design have been elaborated. Further, it will provide an in-depth review of the most suitable peripheral analysis methodologies in place of the proposed structured procedure, to facilitate the selection process of obtaining an optimized KPI set. This KPI set, placed properly in the organization design, will direct performance drivers of a research institute to be on par with the competitiveness of the agriculture industry of a country.
\end{abstract}

Keywords Commercial agriculture $\cdot$ Research institutes $\cdot$ Organization analysis $\cdot$ Performance management $\cdot$ KPI

JEL Classification $\mathrm{O} 13 \cdot \mathrm{O} 21 \cdot \mathrm{O} 32$

\section{Role of Research Institutes Towards Commercial Agriculture}

The commercial agricultural sector in any economy is a diverse sector comprising several branches such as field crop husbandry, horticulture, animal production, dairy farming, fish farming, and agro-processing. Integrating commercial

Prabath Chaminda Abeysiriwardana

abeysiriwardana@yahoo.com; pcabeysiriwardena@wyb.ac.lk

Udith K. Jayasinghe-Mudalige

udith@hotmail.com; udith@wyb.ac.lk

1 Department of Agribusiness Management, Faculty of Agriculture and Plantation Management, Wayamba University of Sri Lanka, Makandura, Gonawila (NWP), Sri Lanka

2 State Ministry of Skills Development Vocational Education Research and Innovation, Sethsiripaya Stage I, Battaramulla, Sri Lanka agriculture of developing countries into the world economy confronts many challenges: overcoming marginalization from global markets, adapting to technological change, and coping with a new institutional environment.

In the first quarter of 2020, the share of agriculture in Sri Lanka's gross domestic product was around 7.3 percent, and the sector provides livelihood and security to around 30 percent of the population (DCS, 2020). This livelihood percentage is quite high, even when issues such as low productivity, less profitability, and natural disasters like the Covid19 pandemic hamper the growth of this sector (Roshana \& Hassan, 2020; Thibbotuwawa \& Hirimuthugodage, 2015). Therefore, a developing country can achieve better competitiveness and commercial position by improving productivity in several different complementary but mutually exclusive dimensions such as process upgrading, product upgrading, functional upgrading, or by integrating numerous functions inside the business, and channel upgrading (differentiated by the technology sector in use or the market that is targeted). 
Therefore, in the context of such advancement, agricultural transformation is expected to shift from low input-low output (low productivity subsistence farming to large scale input-higher output (higher productivity) commercial farming. This ensures more profit and increased competitiveness (Grant et al., 2017).

\section{Avenues for Performance Improvement in Research Institutes}

A researcher may develop agriculture products or services coupled with inventing technologies and innovations that lead to the improvement of their quality, quantity, and price. In light of this, three avenues described below could be identified as the most important in performance improvement of research institutes based on their impact on commercial agriculture (Kristiansen \& Ritala, 2018) and association in competitiveness.

\section{Commercialization}

The sustainability of a research institute in the innovative commercial agriculture field highly depends on its' competitiveness in doing successful applied research in the commercial agriculture field. Innovative agriculture products engrossed by economic potential further open up its commercialization success (Awotide et al., 2016; Goletti et al., 2003; Mahaliyanaarachchi \& Bandara, 2006) resulting in higher productivity in nutrition smart commercial agriculture with improved food security (WB, 2020).

Also, the commercialization of research products tightly binds to research innovation (Gutterson, 2020; Kalaitzandonakes et al., 2018; Sumberg \& Reece, 2004). Although in general, a separate entity involves commercializing the research product/service, research institutions could also play a role in certain aspects of the commercialization process. When dealing with such situations, researchers need to understand the areas to be specifically focused on and the policies of their institutions. Further, driving research institutes' performance towards international research business would make it more competitive and sustainable in the commercial agriculture field (Momaya, 2001, 2019).

\section{Business Linkages}

A company takes a very high risk in its investment for achieving large-scale success in commercial agriculture when it highly depends on using innovative products and services of a research institute. It is easier to control the quality when producing a product in small quantities in a highly controlled laboratory than producing on a large, commercial scale. As it can take years to get a product right, and competitors could enter the market in the meantime, research with business linkages would be the savior for both the research institute and the researcher (Deneke \& Gulti, 2016; Parker et al., 2001).

Some companies have large R\&D departments that are capable of doing much of this work entirely on their own. The others have more limited capacity and may depend on the expertise of a research institution or other external experts for assistance (Fintrac, 2017). Research institutes could thrive in this situation to build industry partnerships.

\section{Adoption of Financial Tools}

A research institute will exist by royalties, fee-for-service, project funding, sponsored research, or government funding (Danziger \& Scott, 2020; Lam, 2011). Other research entities such as research groups and virtual research projects will be more limited and may only be able to operate in a project structure funded by international development donors, research grantors, or the private sector.

GDP, inflation rate, tax rate, FDI, trade, and costs associated with the commercial agriculture sector could be considered as the determinants of competitiveness for innovation-driven commercial agriculture (Momaya, 2001; Rusu $\&$ Roman, 2018). These competitive factors should be carefully analyzed before establishing rules and procedures to encourage and develop the above financial tools in research institutes.

\section{Measuring and Monitoring of Contribution of Research Institutes for Performance Improvement}

Monitoring and measuring business performance can help the research institute to spot new market opportunities, reduce costs, access new customers, and increase its competitiveness among others.

Performance measurement is very useful in the following contexts in commercial agriculture development:

1. To know formally, how well the research work is performing towards its targets.

2. To maximize the success in identifying the market opportunities that exist for it.

3. To avoid being out of the track of the planned research work.

4. To make the research work updated with the environmental changes.

5. To capture market demands for the research work.

Key Performance Indicator (KPI) is a versatile tool that can be used to evaluate the success of an organization in line 
with critical success factors associated with it. It is essential to select the correct KPI set and put it in a proper system to assess business performance, inclusive of the financial performance of the research institute.

Besides, a shared KPI set could be developed for all the research institutes in the commercial agriculture sector to meet the dual challenges of comparability and practicability for establishing KPIs for the development of the commercial agriculture sector (Lydenberg et al., 2010).

\section{KPI as a Role Player in Performance Measurement}

Although it is substantially discussed in literature about the importance of KPI in performance management of a research institute (Agostino et al. 2012; IIRE, 2017; Kahn \& McGourty, 2009; Kolar et al., 2020; Villazon et al., 2020; $\mathrm{Xu} \& \mathrm{Li}, 2016$ ), success stories of using KPI in research institutes working towards commercial agriculture are not reported, or if reported, it is in meager (Cornell University, INSEAD, and WIPO, 2018; Dumanski et al. 1998; NuhoffIsakhanyan et al., 2017). In this context, we propose a kind of procedure for a research institute to follow, when selecting its KPIs to drive innovation in commercial agriculture, given the following conditions satisfied.

1. KPI should exist in a fully awake state in the institute, from its first inception of setting it, right through assigning targets, collecting results, and measuring results.
This will ensure effective and efficient decision-making in the research institute towards its organizational goals.

2. All stakeholders dealing with the organizational KPIs should not be unbonded at any stage of the performance management process to make the KPIs a common property of all stakeholders.

\section{Methods and Discussion}

\section{A Procedure to Adopt and Maintain a Successful KPI Set for a Research Institute for Impactful Research in Commercial Agriculture}

A six-step procedure is proposed for developing a successful KPI set, and maintaining it during performance management of research institutes, for the development of commercial agriculture. Each step will be discussed and rationalized in detail thereafter (Fig. 1).

\section{Step 1. Strategic Review of Organizational Environment}

It is very important to identify specific areas in the business of research institutes by looking at key drivers of success in research institutes for the development of commercial agriculture (Ruttan, 1991; Viviano, 2017) within the context of the overall design of the research institute as depicted in Fig. 2.
Fig. 1 The proposed six-step procedure to be adopted in developing KPIs during the performance management of research institutes
Step 1. Strategic Review of Organizational Environment

-The position in which the institute placed, should be first identified in relation to internal capacities and external challenges.

Step 2. Strategic Review of Existing Performance Management

- It should be found whether any kind of performance measurement system is available (formally or informally) within the research institute.

Step 3. Identify Best Available Improvements, Reconfigurations or Changes for Performance Management in Research Institute in line with Commercial Agriculture Research

- This should be done based on the findings from step 1 and 2 .

Step 4. Enabling Proper KPI Set for Performance Measurement

Step 5. Keep KPI Set Vigourous in Organizational Design

Step 6. Automating Performance Management

- This could be done simultaneous with step 4. 


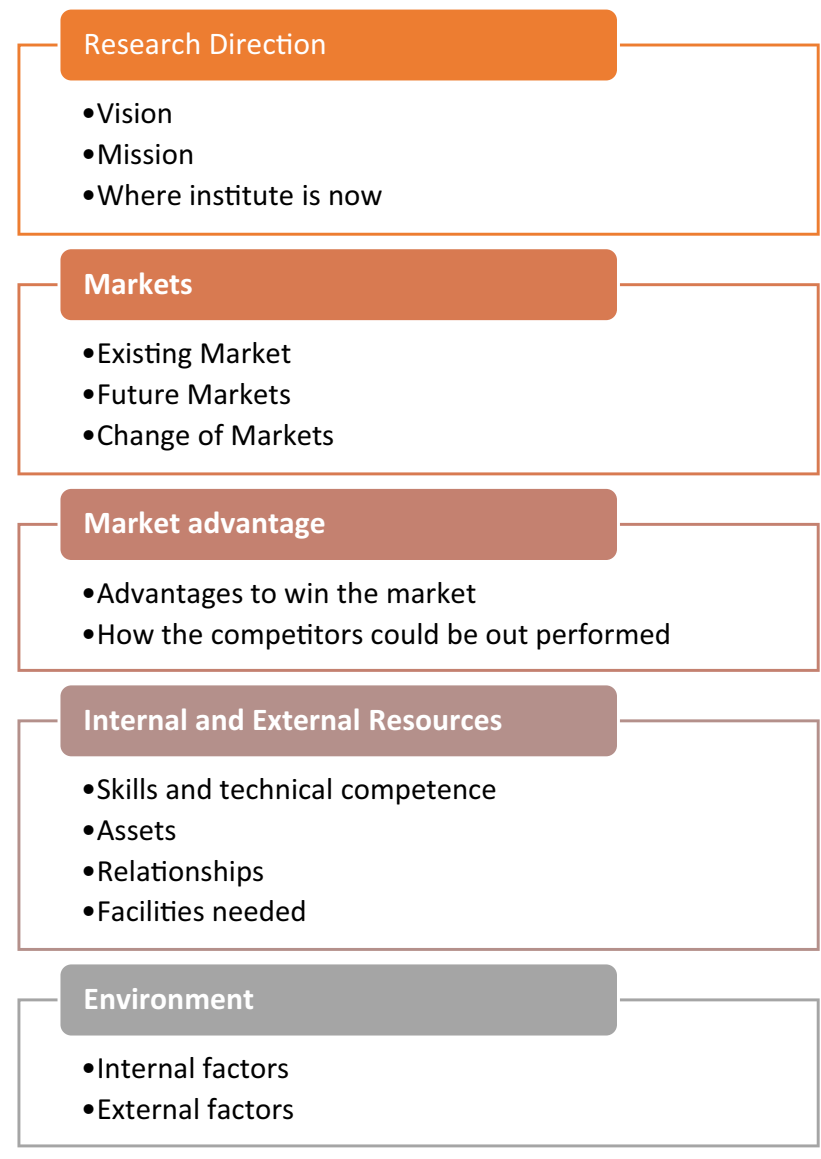

Fig. 2 The specific areas in the business of a research institutes work for commercial agriculture

There are two important elements responsible for the performance of the research business:

1. Core business activities such as the production of inventions and innovations that it develops, or services that it provides with existing knowledge, to be competitive in the commercial agriculture sector.

2. Then research institute should identify what makes it successful, how to improve it, and how to launch new or complementary products or services from it.

Research institute should analyze the following in its existence:

1. How effective it in matching its' goods and services to its customers' needs?

2. Which of its products and services are successful? Are some not performing as planned?

3. Do any of the products generate a high percentage of sales and high-profit margins?

4. What causes problems for the research business?

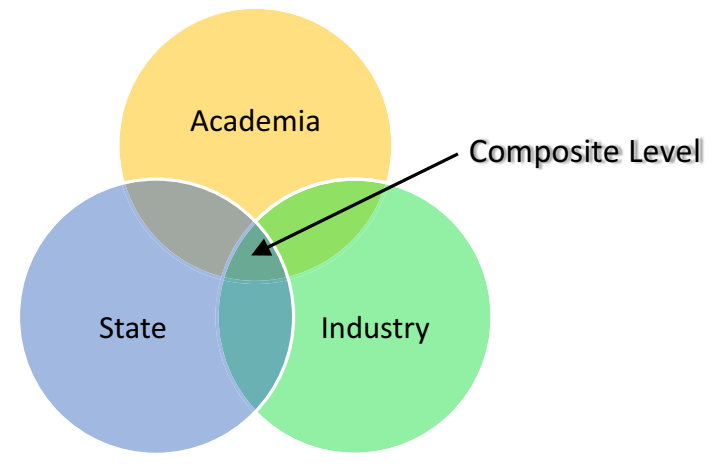

Fig. 3 The triple helix model Source: Etzkowitz and Leydesdorff (2000)

5. Does it need more regular financial management reviews?

According to the triple helix model (Etzkowitz \& Leydesdorff, 2000), public research labs, firms, and the government brought together by the global market, and the generation of new technological knowledge would be loosely integrated if they are not properly communicated, negotiated, and coordinated (Fig. 3). Therefore, it is very important to check whether the composite organizational level could be established with research institutes for the success of commercial agriculture. Here, the state will represent public research institutes work towards commercial agriculture.

Revisiting of success factors of research institutes is needed to support the invasion of new technologies like biotechnology nanotechnology and artificial intelligence. In this new ecosystem, the research institute should focus its attention to improve the following area of concern:

1. Publication and patenting that facilitate the transformation of knowledge and technology into marketable products.

2. The increased productivity of research knowledge and innovation in economic development.

3. Competitors and unfavoured internal environment, which lead to a reduction in research activities and changes in the number and quality of professionals attracted to a research institute. Research institute national and global rankings may also suffer if this is not taken into proper consideration (Johnson, 2013). In this context, competitor analysis would help in differentiating the products and services and analyzing the competitor's product development initiatives (Invest Northern Ireland, 2020).

4. Research institutes need to assess their customer base and market positioning as a key part of the process. This will help the research institutes to re-evaluate market factors such as: 
I. Changes in the market.

II. New and emerging services.

III. Changes in the customers' needs.

IV. External factors such as the economy and new technology.

V. Changes in competitive activities.

Business analysis models are useful tools and techniques that could help in understanding the research institute environment and thinking more strategically about research business. Some of them are:

1. SWOT (strengths, weaknesses, opportunities, threats) analysis.

2. PESTLE (political, economic, social, technological, legal, and environmental) analysis.

3. Competitiveness Assets-Processes-Performance.

4. Scenario planning.

5. Porter's Five Forces framework.

\section{SWOT}

Performing SWOT analysis on the performance of research institutes work towards commercial agriculture development may be the best initial option to get a view of how the research institute is doing in the research field in general and among its competitors (Mutenje et al., 2018). SWOT analysis could be used considering the customer's perspective to acquire better strategic plans and decisions for the research institute.

SWOT analysis may help research institutes to attain success towards research and developments of Commercial Agriculture in the following ways:

1. Capitalize on the strengths of the research institute.

2. Minimize the weaknesses.

3. Thrive on opportunities.

4. Reduce the impact of any threats.

SWOT analysis should be done separately for each institute in the context of the present contribution of research towards commercial agriculture.

After completing a SWOT analysis, a research institute may attempt to match its strengths with opportunities and convert weaknesses into strengths. In this process research institute will need to come up with some recommendations and strategies based on the results (Shewan, 2017; www. mindtools.com, 2019).

\section{PESTLE}

PESTLE analysis may be more useful than SWOT when a research institute wants to emphasize and analyze the external factors more than the internal factors that influence its business (UKEssays, 2018).

\section{Competitiveness Assets-Processes-Performance: A Tool to Identify Competitive Performance Drivers}

Simple and widely tested approach such as Competitiveness Assets-Processes-Performance has higher flexibility for adapting to different contexts and could be used to identify and introduce performance drivers responsible for different competitiveness such as improved quality products, social investment, ecological ambitions, and the share of eco-industries for commercial agriculture development (Momaya, 2001).

Further, existing performance indicators and rankings may be analyzed to deconstructing the competitiveness of research institutes towards innovative and sustainable commercial agriculture to identify areas of improvement in research conducting (Bristow, 2010).

\section{Scenario Planning}

Scenario planning helps leaders to develop a detailed, internally consistent picture of a range of plausible outcomes as a research institute evolves in its business (Lindgren \& Bandhold, 2009). This is not usually possible with SWOT analysis.

\section{Porter's Five Forces Framework}

Research institute may use Porter's Five Forces framework if it wants to map its competitiveness factors within the same research industry (Grundy, 2006).

\section{Step 2. Strategic Review of Existing Performance Management in Research Institute}

Depending on the vision and the mission of the institute, the following key areas could be considered in performance measurements:

1. Customers of the institute-e.g. how many customers the institute has, how often those customers are involved with the institute, and how many customers the institute has lost or gained.

2. Customer service-e.g. waiting times for accepting service or delivering service, reasons customers have complained.

3. Market share-e.g. if the institute share of the market is increasing or decreasing against competitors. 
4. The staff of the institute-e.g. satisfaction levels, work quality, carder vacancy, and job abandoning.

Identified areas for performance measurements should have performance targets. These will give everyone in the research business a clear idea of what they need to aim for, individually and collectively. It should be checked whether the main strategic goals have been broken down into smaller targets to be easily managed. These smaller targets, once completed, move the institute closer to its final goal.

SWOT analysis is a technique that can be applied to a wide range of scenarios, not just as a technique to find the overview dynamism of a business (Shewan, 2017). KPI system could be considered as a kind of unique structure established to attain a particular task of the performance measurement. Therefore, SWOT analysis could be used on that structure to ascertain how well a KPI system is positioned in performance measurement of research institutes. SWOT analysis for using existing KPIs in the research institute towards the success of commercial agriculture can be performed to extract the best KPIs, and introduce new KPIs to the research institute.

KPIs involved with the performance of research institutes towards commercial agriculture, directly and indirectly, are selected. SWOT analysis is performed on them to identify their validity on performance measurement.

Side with the SWOT, surveys may be used to construct a satisfaction index of existing performance measurements (Hwang et al., 2020; Shaw, 1999).

\section{Step 3. Identify Best Available Improvements, Reconfigurations, or Changes for Performance Management}

It is necessary to identify correct changes to the right measurements that focus on the areas and elements of research business performance and make the institute successful and profitable when dealing with the research done towards commercial agriculture.

For example, a research institute that produces low-cost equipment to be used in the agriculture field might measure the number of innovative products produced or supported in this regard for a specific period. The research institute that produces high-end equipment using new technologies might focus on measuring the number of technology errors reduced or the number of technologies introduced. A research institute may change its focus on business strategies considering new customer service requested and will develop measures around that specific area accordingly. Thus, the institute would naturally be aware of and admit that performance measures may change as the research business matures and becomes competitive towards commercial agriculture in the global context (Moirangthem \& Nag, 2020) (Pettigrew \& Whipp, 1992).

\section{Step 4. Enabling Proper KPI Set for Performance Measurement}

As the vision and mission are already set for the research institutes, usually its objectives and strategies are considered for setting KPIs. The objectives and strategies could be refurnished with the success of research institutes' performance towards commercial agriculture as necessary.

The critical success factors identified from the first SWOT analysis and KPIs in the strengths category of the second SWOT analysis could be compared to obtain the best fit KPI model for the performance measurement of research institutes towards the success of commercial agriculture.

\section{KPIs that Suture the Performance Drives}

Several types of KPIs can be used in the research business. Therefore, special care should be taken to select the most appropriate KPIs that promise critical performance drives, when used in research business and strategy.

Most KPIs used in research institutes will focus on one of these objectives:

1. Improve research revenue.

2. Increase efficiency and effectiveness of research outputs/ outcomes.

3. Improve customer satisfaction over research outputs.

Usually, a research institute may face many difficulties in achieving its objectives in strategies if it uses an improper KPI set as follows:

1. Too many KPIs can weaken the focus on areas identified as important and critical to the business.

2. A KPI that does not have clear connections to business objectives.

3. Lack of strategic mechanism to select KPIs.

4. Lack of strategic mechanism to abandon the performance measures lead to a failure in performance measuring.

Quality KPI has so many characteristics that help it stands against the test of time (Badawy et al., 2016).

Some examples of KPIs:

1. Average time to complete a research product.

2. Percentage of research completed on time.

3. Cost of service delivery.

4. Customer ratings of research service. 


\section{How KPIs should be Integrated into the Performance Measurement System of a Research Institute}

Before selecting KPIs for the institute, they should be evaluated whether the institute has control over the business environment related to aspects measured by these KPIs. For example, rapid changes in frontier technologies may be a crucial factor of performance for a given research business, but the institute may not use the power of Artificial Intelligence as a KPI because the research institute has no power to invest the minimum required to be a leader in it. By contrast, an institute can control its business' exposure to secondary applications made using existing frontier technologies such as $\mathrm{AI}$ and use it as a useful KPI.

\section{Set KPIs for Financial Performance Measurement}

Financial performance measurement helps the institute to examine its business goals and plan effectively for improving the financial sustainability of the institute. The most important aspects concerning this should be:

1. Capital—existing capital should be measured comparing to the industry standard.

2. Cost-keep institute costs under review. Make sure that customers are not underpaying for any research business. This will help to price the research product or service efficiently.

3. Growth-continuous adaptations in financing to accommodate the research business' changing needs and growth.

It is not an exception for a research institute to consider the customer as an important aspect of its business strategy. Leading companies tend to prioritize customer-related KPIs to gain competitive advantage (MIT Sloan Management Review; Google, 2018). In this scenario, the research institute may measure performance in terms of customer retention, customer satisfaction, service response time, etc., to meet customer requirements and satisfy their expectations.

Some common customer-centric KPIs that could be used in research institutes are:

1. Net promoter score-measures how likely your customers are to recommend you.

2. Customer retention rate-your ability to keep a customer over time.

3. Quality of service—including reliability, assurance, and responsiveness.

4. Employee engagement-staff motivation can affect quality customer service.
Some institutes have found that shared KPIs could be explicitly used to promote cross-functional collaborations. Analytically superior organizations use algorithms to identify and weight KPI attributions to desired marketing or customer outcomes (Schrage, 2018). Coordination among research institutes is needed to eliminate institutes' specific interests and motives to be associated with common KPI set to avoid conflicts in achieving common goals of commercial agriculture development. This will form a common KPI set justifiable for all research institutes in common.

\section{Step 5. Keep KPI Set Vigorous in Organizational Design}

Do research institutes avoid completing performance-related tasks? This is a question to be asked and revisited from time to time as most research institutes may fall into the trap that it has been all done once it has created some KPI set for the research institute.

There are two things that research institutes must do in this regard.

1. Setting SMART targets

2. Benchmarking

\section{Setting SMART Targets}

Usually, a KPI by definition is specific and measurable, and so the research business targets associated with it have the first two qualities of a SMART KPI (specific, measurable, achievable, realistic, and time-bound). The other three qualities should be carefully addressed with the consultation of all stakeholders of the research organization in the context of commercial agriculture.

After setting the research business targets, the institute should assign clear responsibility for delivering each of them (Kenny, 2020). Institute top-level strategic objectives may be abstract. However, its KPI targets should be concrete and tightly owned by a department, group, or individual (FrancoSantos \& Bourne, 2008).

\section{Benchmarking}

A research institute can use benchmarking to identify the 'best in class' performance of other research businesses, including competitors to enhance its specific business process or activity. This ensures competitiveness among research institutes to produce high impactful research towards innovative commercial agriculture.

By carrying out performance benchmarking, the research institute should aim to answer the following questions: 
1. Who is the best performer in the commercial agriculture research sector/industry?

2. What makes them the best?

3. What lessons can research institutes learn from them?

4. What actions can the research institute take to improve performance?

Research institutes can carry out a benchmarking exercise as a one-off event or as a continuous process.

Benchmarking financial performance is also an important part of the research business as many research businesses may fail at inadequate financial management or planning (Nguyen \& Canh, 2020).

\section{Which Authority Should be Empowered to Define KPIs for Research Institutes in Commercial Agriculture Development}

A research institute needs to establish a KPI set in its strategic planning process in a much more inclusive manner. All researchers need to understand the organization's mission, vision, values, and strategy to make their effort successful in achieving objectives align with the organization's critical success factors. Also, if there is organizational support for building constructive feedback, that environment will encourage, develop and drive goal-directed performance improvement. Separate trained staff with Chief Measurement Officer (CMO) would be ideal in leading the performance measurement of the research institute. CMO job in this context would be part psychologist, part teacher, part salesperson, and part project manager. It will facilitate the intellectual rigor in a research institute on the journey from average to good and finally to great (Parmenter, 2015).

Research institutes can link performance with rewards and recognition in sound performance management, which is seen as fair and equitable. Proper recognition of a top performer resulting increased job satisfaction and could be implemented through a consistent process of formal recognition events, informal public recognition, or privately delivered feedback. An employee performing at the same level in any department should receive similar rewards. Thus, the human factor connected to performance management will give the research institute an added advantage to be competitive in its research activities towards developing commercial agriculture.

\section{A Research Institute in Full Participation}

In performance management especially in performance appraisals, research institutes should give due consideration to the existing culture in its organization design. A culture of open and honest communication supports effective performance management. Employees must be able to discuss performance honestly and consider how to make improvements to move forward in innovation drive mixed with disruptive technologies.

\section{Step 6. Automating Performance Management}

The performance management process must grow by information with an increased decision supporting with minimum human intervention to avoid resistance and non-participation of researchers and other staff. Data for many indicators are often not collected regularly, and quality of data are a key problem for the estimation of some indicators (Bracco et al., 2019).

Information technology (IT) will be an enabler in measuring the performance of research businesses through IT systems by logically gathering data.

Research institutes should take care of transforming their business through an automated performance management solution. Some solutions offer simple electronic appraisal systems, while others offer complete best-of-breed performance and goal management systems (SAP, 2019). The best solutions may include advanced functionalities like instant form routing and paperless processes, goal tracking, and cascading functionality for complete visibility and alignment.

A few software may be required to function harmoniously to make an effective performance management system. Some software may be used to set targets and allocate the resources to achieve institute goals while other software may be used to examine operational data. The integrated system will help the research institute to analyze results for improved efficiency and productivity in research business operations in real-time (Duggan, 2019).

\section{Implications, Direction for Future Research and Conclusion}

We here underlined the importance of performance management of research institutes in the context of the development of commercial agriculture in the modern era. It is emphasized that care has to be given in designing and implementing it correctly. Implemented in such a balanced way on the sides of institute performance and its key stakeholder's expectations including its employees, KPIs can significantly contribute to the long-term sustainability of research infrastructure. Given the above, we propose a 6-step procedure to obtain an optimized KPI set for the institute that works for commercial agriculture. In this procedure, the importance of using peripheral analysis methodologies is highlighted with a special focus on the competitiveness factor of research institutes towards the 
success of commercial agriculture in the economy of a country.

It is also worthwhile to do more research in areas like performance measurements in line with the competitiveness Assets-Processes-Performance framework (Momaya, 2001; Ajitabh \& Momaya, 2004) aimed at exploring competitiveness linkages that could facilitate the transformation of mature to emerging research institutes. The results of such studies would provide a good foundation stone to establish a universally accepted approach to define and measure competitiveness in the commercial agriculture field.

As a policy measure, institutes may prepare their own manual for the performance management process based on our proposed procedure and update the manual every year as an activity of their action plan. In this endeavor, it would be worthwhile to introduce policies in support of promoting competitiveness among research institutes to work harmoniously towards innovative commercial agriculture.

\section{Key Questions Reflecting Applicability in Real Life}

In a competitive world, research institutes need to be smart in their research business. KPI is a tool that would drive the research business performance in the right direction by exposing new avenues of improvement. If rightly identified and applied in the real life of the research business, KPI would be a champion of research success in commercial agriculture. Following are the key questions to be answered in a research ecosystem by the wealth of the KPI for innovative commercial agriculture.

1. What are the Critical Success Factors associated with the performance drives of the research business for innovative commercial agriculture?

2. How can the research institute identify the KPIs responsible for those Critical Success Factors in the domain of commercial agriculture success?

3. What is the role of peripheral analysis methods in adopting KPIs in a research institute for the development of commercial agriculture?

4. Why KPI in a good performance management system would be a perfect tool to harmonize the performance drives of a research institute with the competitiveness of the research business for the success of commercial agriculture?

5. What would be a good procedure to sort out the best fit KPI set for realigning the vision and mission of a research institute with the objectives of the research for commercial agriculture development?
Acknowledgements We thank the anonymous reviewers and the editors for their helpful comments in improving the quality of this manuscript.

Author contributions Prabath Chaminda contributed to the conceptualisation, design and draft ofthe work. Udith K. contributed to revise it. Prabath Chaminda confirms that the manuscript has been read and approved for submission, by all the named authors.

Funding The authors have no relevant financial or non-financial interests to disclose.

\section{Declarations}

Conflict of interest We know of no conflicts of interest associated with this publication, and there has been no outside funding for this work that could have influenced its outcome.

\section{References}

Agostino, D., Arena, M., Azzone, G., Dal Molin, M., \& Masella, C. (2012). Developing a performance measurement system for public. International Journal of Business Science \& Applied Management, $7(1)$

Ajitabh, A., \& Momaya, K. (2004). Competitiveness of firms: Review of theory, frameworks and models. Singapore Management Review, 26(1), 45-61.

Awotide, B. A., Karimov, A. A., \& Diagne, A. (2016). Agricultural technology adoption, commercialization and smallholder rice farmers' welfare in rural Nigeria. Agricultural and Food Economics. https://doi.org/10.1186/s40100-016-0047-8.

Badawy, M., Ahmed, A.E.-A., Idrees, A., Hefny, H., \& Hossam, S. (2016). A survey on exploring key performance indicators. Future Computing and Informatics Journal. https://doi.org/10.1016/j.fcij. 2016.04.001.

Bracco, S., Tani, A., Calıcıoglu, O., Gomez San Juan, M., \& Bogdanski, A. (2019). Indicators to monitor and evaluate the sustainability of bioeconomy. Overview and a proposed way forward. . FAO.

Bristow, G. (2010). Critical reflections on regional competitiveness: Theory. . Routledge. https://doi.org/10.4324/9780203865408.

Cornell University, INSEAD, and WIPO. (2018). Annex 4: Measuring innovation in agriculture and food systems. In I. A. Cornell University, The global innovation index 2017 (10 ed.). WIPO. Retrieved from https://www.wipo.int/edocs/pubdocs/en/wipo_ pub_gii_2017-annex4.pdf

Danziger, R., \& Scott, J. (2020). Government royalties on sales of biomedical products developed with substantial public funding. The Journal of Technology Transfer. https://doi.org/10.1007/ s10961-020-09821-6.

DCS. (2020). National accounts of Sri Lanka 1st quarter of 2020. Department of Census and Statistics (DCS). http://www.statistics. gov.lk/Resource/en/NationalAccounts/2010/reports/Production/ 2020.08.04/detail_note_2020q1_english.pdf

Deneke, T., \& Gulti, D. (2016). Agricultural research and extension linkages in the Amhara Region, Ethiopia. In F. Gatzweiler, \& J. von Braun (Eds.), Technological and institutional innovations for marginalized smallholders in agricultural development. Springer. https://doi.org/10.1007/978-3-319-25718-1_7

Duggan, T. (2019). How to measure business performance with information technology. Retrieved from https://smallbusiness. 
chron.com/: https://smallbusiness.chron.com/measure-businessperformance-information-technology-805.html

Dumanski, J., Terry, E., Byerlee, D., \& Pieri, C. (1998). Performance indicators for sustainable agriculture. The World Bank.

Etzkowitz, H., \& Leydesdorff, L. (2000). The dynamics of innovation: From national systems and 'Mode 2' to a triple helix of university-industry-government relations. Research Policy, 29(2), 109-123. https://doi.org/10.1016/S0048-7333(99) 00055-4.

Fintrac. (2017). Success factors for commercializing agricultural research, a report by feed the future partnering for innovation. USAID. Retrieved from https://static1.squarespace.com/static/ 5a7b7b36d55b416e7a7bcd2b/t/5ab5143088251b2e6b196cf5/ 1521816625457/FTF+Partnering+for+Innovation_8+Success+ Factors_Research.pdf

Franco-Santos, M., \& Bourne, M. (2008). The impact of performance targets on behaviour: A close look at sales force contexts. Cranfield School of Management. Retrieved from https://dspace.lib. cranfield.ac.uk/bitstream/handle/1826/4222/Impact_of_perfo rmance_targets_on_behaviour.pdf?sequence $=1 \&$ isAllowed $=\mathrm{y}$

Goletti, F., Purcell, T., \& Smith, D. (2003). Concepts of commercialization and agricultural development. http://www.agrifoodco nsulting.com/. Agrifood Consulting International. Retrieved from http://www.fao.org/tempref/AG/Reserved/PPLPF/Docs/Reports\% 20\&\%20Papers/PAP_MT_EA_AC_Commercialization\&AgriD evelopment_Goletti.pdf

Grant, W., Guilleminault, D., \& Sarma, K. (2017). Commercial agriculture portfolio review: Final report.

Grundy, T. (2006). Rethinking and reinventing Michael Porter's five forces model. Strategic Change, 15(5), 213-229. https://doi.org/ $10.1002 /$ jsc. 764 .

Gutterson, N. (2020). Commercialization and applications of agricultural biotechnology. In C. Shimasaki (Ed.), Biotechnology entrepreneurship (2nd ed., pp. 385-398). Academic Press. https://doi. org/10.1016/B978-0-12-815585-1.00027-9

Hwang, G., Han, J.-H., \& Chang, T.-W. (2020). An integrated key performance measurement for manufacturing operations management. Sustainability. https://doi.org/10.3390/su12135260.

IIRE. (2017). Interim evaluation of science foundation Ireland research centres programme. Indecon International Research Economists (IIRE), Science Foundation Ireland. Retrieved from https://www. sfi.ie/research-news/publications/organisational-publications/SFIResearch-Centres-Interim-Evaluation-Indecon-Report.pdf

Invest Northern Ireland. (2020). Measure performance and set targets. Retrieved from nibusinessinfo.co.uk: https://www.nibusinessinfo. co.uk/content/measure-performance-and-set-targets

Johnson, A. M. (2013). Improving your research management. . Elsevier B.V.

Kahn, C., \& McGourty, S. (2009). Performance management at R\&D organizations. The MITRE Corporation. Retrieved from https:// www.mitre.org/sites/default/files/pdf/09_2188.pdf

Kalaitzandonakes, N., Carayannis, E., Grigoroudis, E., \& Rozakis, S. (Eds.). (2018). From agriscience to agribusiness. Springer. https:// doi.org/10.1007/978-3-319-67958-7

Kenny, G. (2020). Create KPIs that reflect your strategic priorities. Retrieved from https://hbr.org/2020/02/create-kpis-that-reflectyour-strategic-priorities

Kolar, J., Harrison, A., \& Gliksohn, F. (2020). Key performance indicators of research infrastructures/2: Executive summary. https:// www.accelerate2020.eu. Retrieved from https://www.accelerate 2020.eu/key-performance-indicators-of-research-infrastructures2-executive-summary/

Kristiansen, J. N., \& Ritala, P. (2018). Measuring radical innovation project success: Typical metrics don't work. Journal of Business Strategy, 39(4), 34-41. https://doi.org/10.1108/ JBS-09-2017-0137.
Lam, A. (2011). What motivates academic scientists to engage in research commercialization: 'Gold', 'ribbon' or 'puzzle'? Research Policy, 40(10), 1354-1368. https://doi.org/10.1016/j. respol.2011.09.002.

Lindgren, M., \& Bandhold, H. (2009). Scenario planning the link between future and strategy (2 ed.). Palgrave Macmillan. https:// doi.org/10.1057/9780230233584

Lydenberg, S., Rogers, J., \& Wood, D. (2010). From Transparency to Performance, Industry-Based Sustainability Reporting on Key Issues. Harvard Kennedy School. Retrieved from https://iri.hks. harvard.edu/files/iri/files/iri_transparency-to-performance.pdf

Mahaliyanaarachchi, R. P., \& Bandara, R. M. (2006). Commercialization of agriculture and role of agricultural extension. Sabaragamuwa University Journal, 6(1), 13-22.

MIT Sloan Management Review; Google. (2018). Customer-focused KPIs fuel the future of business. MIT Sloan Management Review. Retrieved from https://sloanreview.mit.edu/customer-focusedkpis-fuel-the-future-of-business/

Moirangthem, N., \& Nag, B. (2020). Developing a framework of regional competitiveness using macro and microeconomic factors and evaluating sources of change in regional competitiveness in India using Malmquist Productivity Index. International Journal of Global Business and Competitiveness, 15, 61-79. https://doi. org/10.1007/s42943-020-00016-2.

Momaya, K. (2001). International competitiveness: Evaluation and enhancement. Hindustan Publishing Corporation.

Momaya, K. (2019). The past and the future of competitiveness research: A review in an emerging context of innovation and EMNEs. International Journal of Global Business and Competitiveness, 14, 1-10. https://doi.org/10.1007/s42943-019-00002-3.

Mutenje, M., Ghimire, S., Wösten, H., Bloem, E., Mutimura, M., Dechassa, N., \& Magalasi, M. (2018). An overview and SWOT analyses of sustainable agriculture intensification systems and agricultural extension systems: (Ethiopia, Kenya, Malawi, Rwanda, South Africa and Tanzania). European Commission. Retrieved from https://ec.europa.eu/research/participants/docum ents/downloadPublic?documentIds $=080166 \mathrm{e} 5 \mathrm{bca}$ ac1 $1 \mathrm{a} \& \mathrm{appId}=$ PPGMS

Nguyen, B., \& Canh, N. (2020). Formal and informal financing decisions of small businesses. Small Business Economics. https://doi. org/10.1007/s11187-020-00361-9.

Nuhoff-Isakhanyan, G., Kruize, J. W., \& Berlin, A. (2017). Internet of food and farm 2020: KPI catalogue for each use case. https:// www.iof2020.eu. Retrieved from https://www.iof2020.eu/deliv erables/d4.1-kpi-catalogue-for-each-uase-case.pdf

Parker, D., Castillo, F., \& Zilberman, D. (2001). Public-private sector linkages in research and development: The case of U.S. agriculture. American Journal of Agricultural Economics, 83(3), 736741. Retrieved from http://www.jstor.org/stable/1245109

Parmenter, D. (2015). Key performance indicators, developing, implementing, and using winning KPIs (3rd ed.). Wiley.

Pettigrew, A., \& Whipp, R. (1992). Managing change and corporate performance. In K. Cool, D.J. Neven, I. Walter, European industrial restructuring in the 1990s. Palgrave Macmillan. https://doi. org/10.1007/978-1-349-12582-1_9

Roshana, R. M., \& Hassan, N. (2020). Challenges and opportunities of COVID-19 outbreak on Sri Lankan agri-food sector. . Sri Sairam Group of Institutions.

Rusu, V. D., \& Roman, A. (2018). An empirical analysis of factors affecting competitiveness of C.E.E. countries. Economic Research-Ekonomska Istraživanja, 31(1), 2044-2059. https://doi. org/10.1080/1331677X.2018.1480969

Ruttan, V. W. (1991). Challenges to agricultural research in the twenty-first century. In R. Landau, Technology and economics (pp. 85-105). National Academy of Sciences. https://doi.org/10. $17226 / 1767$ 
SAP. (2019). 10 ways to improve the performance management process. Retrieved from https://www.sap.com: https://www.sap.com/ insights/hr/optimize-monitoring-performance-and-goal-manag ement.html

Schrage, M. (2018). Five categories to focus your KPIs. Retrieved from https://sloanreview.mit.edu/article/five-categ ories-to-focus-your-kpis/

Shaw, R. (1999). Measuring, managing and improving the performance of CRM. Interactive Marketing, 1(1), 44-58. https://doi.org/10. 1057/palgrave.im.4340005

Shewan, D. (2017). How to do a SWOT analysis for your small business (with examples). https://www.wordstream.com: https://www. wordstream.com/blog/ws/2017/12/20/swot-analysis

Sumberg, J., \& Reece, D. (2004). Agricultural research through a 'new product development' lens. Experimental Agriculture, 40(3), 295314. https://doi.org/10.1017/S0014479704002030.

Thibbotuwawa, M., \& Hirimuthugodage, D. (2015). Policy reforms for a productive agriculture sector. In Sri Lanka state of the economy 2015 report. Institute of Policy Studies. Retrieved from https:// www.ips.lk/wp-content/uploads/2018/07/Policy-Reforms-for-aProductive-Agriculture-Sector.pdf

UKEssays. (2018). SWOT and PESTEL analysis of Nestle. Retrieved from UKEssays: https://www.ukessays.com/essays/marketing/ swot-and-pestel-analysis-of-nestle-marketing-essay.php?vref $=1$

Villazon, C. C., Pinilla, L. S., Olaso, J. R., Gandarias, N. T., \& Lacalle, N. L. (2020). Identification of key performance indicators in project-based organisations through the lean approach. Sustainability. https://doi.org/10.3390/su12155977.

Viviano, F. (2017). This tiny country feeds the world. National Geographic Magazine. Retrieved from https://www.nationalgeograp hic.com/magazine/article/holland-agriculture-sustainable-farming

WB. (2020). Nutrition smart agriculture: When good nutrition is good business. Retrieved from The World Bank (WB): https://www. worldbank.org/en/topic/agriculture/publication/nutrition-smartagriculture-when-good-nutrition-is-good-business

www.mindtools.com. (2019). www.mindtools.com. Retrieved from PEST analysis, identifying "Big Picture" opportunities and threats: https://www.mindtools.com/pages/article/newTMC_09. htm

$\mathrm{Xu}, \mathrm{F} .$, \& Li, X. (2016). The changing role of metrics in research institute evaluations undertaken by the Chinese Academy of Sciences (CAS). Palgrave Communications. https://doi.org/10.1057/palco mms.2016.78.

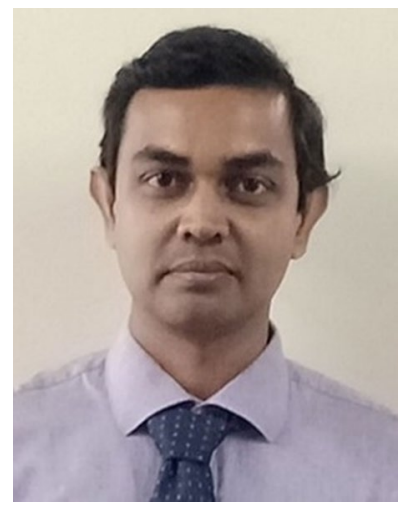

Prabath Chaminda Abeysiriwardana received an M.Sc. degree in computer science from the University of Peradeniya, Sri Lanka, and two BSc degrees in Information Technology and BioScience from the Sri Lanka Institute of Information Technology and the University of Kelaniya, Sri Lanka, respectively. He currently works as a Deputy Director at the State Ministry of Skills Development Vocational Education Research and Innovation. He is also a postgraduate student at the Wayamba

University of Sri Lanka. His current research interests include the Key Performance Indicators and their use in research institutes for commercial agriculture development. ORCID: https://orcid.org/0000-00030300-2020, ResearcherID: E-4779-2014.

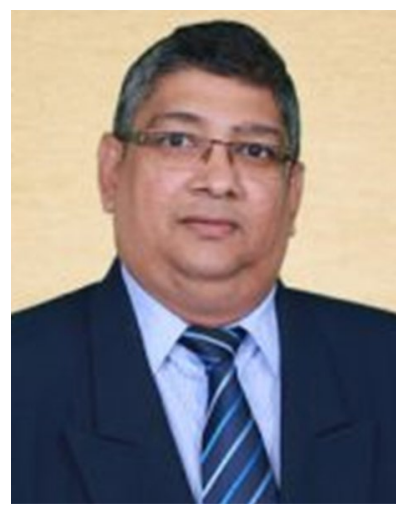

Udith K. Jayasinghe-Mudalige is the Vice-Chancellor of the Wayamba University of Sri Lanka (WUSL). He serves as the Senior Professor and the Chair of the Department of Agribusiness Management, Faculty of Agriculture \& Plantation Management of WUSL. He is a recipient of the 'Fulbright Teaching \& Research Fellowship' (USA); 'Endeavour Postgraduate Research Fellowship' (Australia); 'Senior Fellow of Staff \& Educational Development Association' (SFSEDA, UK); 'Certi-

fied Development Project Manager' (CDPM®, USA) and 'Chartered Environmental Professional' (CEnvP., SL) as well as the 'Presidential' 'National Research Council', 'National Science Foundation', 'Young Scientists' and University Research Awards in multiple occasions to remark his contribution as an academician/ researcher globally. ORCID: https://orcid.org/0000-0002-1806-6273. 